\title{
Inclusãa: ensino de Geografia para alunos surdos, com um olhar sobre a paisa- gem a partir de uma visão freireana
}

\section{Inclusion: gengraphic education for deaf students, with a look at the landscape from a freireana vision}

Jean Volnei Fernandes*

\begin{abstract}
Resumo:
Este artigo tem por objetivo fazer uma análise de questões inerentes à educação inclusiva, a categoria geográfica Paisagem e as diferentes formas de abordagem, que se pode utilizar no trabalho docente, com alunos surdos a partir de uma visão freireana. Em seguida apresenta-se, os principais conceitos de Paisagem, que foram teorizados pelas diferentes escolas que escreveram sobre o assunto, destacando o caráter humanista para alguns autores, e os aspectos físicos para outros. Assim sendo, procede-se uma análise, a partir das experiências vivenciadas em sala de aula, como professor de Geografia, das principais considerações e observações, a respeito do estudo da Paisagem para alunos surdos pautados nos conceitos criados por Paulo Freire e na metodologia pesquisa-ação, como elemento investigativo, bem como a forma através das quais estes alunos podem construir um conceito próprio de Paisagem. Para tanto, considera-se a utilização de fatores que sejam significativos para sua aprendizagem, dentre eles: conversa com os alunos sobre questões relacionadas ao meio ambiente; conceito de Paisagem; participação de um interprete de Libras; vídeo sobre o tema e visita ao lixão da cidade. Tais ações contribuíram para que os alunos compreendessem e identificassem as transformações ocorridas na Paisagem, a partir da atuação do homem, dentro de uma análise reflexiva sobre a realidade que o cerca.
\end{abstract}

\begin{abstract}
:
This article aims to analyze issues relating to inclusive education, geographical category landscape and the different ways of approach, which can be used in teaching work with disabled students hearing from a Freire's vision. Then presents itself, the main landscape's concepts that have been theorized by different schools who have written on the subject, emphasizing humanistic character for some authors, and the physical aspects to others. Therefore, make an analysis, from the experiences lived in the classroom as a teacher of Geography, the main considerations and observations about the landscape study for deaf students lined the concepts created by Paulo Freire and action research methodology, as an investigative element, and the way through which these students can build their own concept of landscape. For this, we consider the use of elements that are meaningful to their learning, among them: talk with students on issues related to the environment; concept of landscape; participation of an interpreter pounds; video about the subject and visit to the city dump. Such actions helped the students understand and identify the transformations in the landscape, from the man acting within a reflective analysis of the reality that surrounds it.
\end{abstract}

* Professor de Geografia da SEDF, atua na sala de recursos de deficiência auditiva. Mestre em Geografia pela UNB
Palavras-chave:

Ensino de Geografia, Surdez, Paulo Freire

Key-Words:

Geography Education, Deafness, Paulo Freire 


\section{INTRODUÇÃO}

O referido artigo procura apresentar a correlação entre Paisagem, alunos surdos e a visão freireana de aprendizagem, utilizando a metodologia da pesquisa-ação compreendida em sua dimensão transformadora e emancipatória. Para tanto, referenciou-se no conceito clássico de Paisagem que pode ser definido como, uma porção de território avistada por um observador a partir de certo ponto, privilegiando os aspectos visíveis.

Partindo desse pressuposto, Paisagem pode ser vista como uma categoria que, bem trabalhada, pode ser muito interessante no processo de ensino-aprendizagem para pessoas surdas, uma vez que é através da visão, que este grupo percebe e interage com o mundo externo, levando-os a conhecerem tanto os aspectos naturais como os humanos que estão envolvidos no estudo da Paisagem.

Nesse contexto o pensamento de Paulo Freire, dentro da chamada Pedagogia Dialógica-problematizadora, pode ser utilizada no estudo da Paisagem, a partir do momento em que se estabelece o empoderamento individual e coletivo do aluno surdo, desenvolvendo assim condições para que o aluno surdo crie seus próprios conceitos no tocante a Paisagem dentro de um processo emancipatório e libertador. Paulo Freire (1981) também problematizou os aspectos políticos e ideológicos da educação indicando a necessidade de conhecer a realidade com a qual, ou na qual atuamos.

Os alunos surdos enfrentam inúmeras dificuldades para participar da educação escolar regular. Tais dificuldades estão relacionadas a fatores ligados principalmente a comunicação, as metodologias de ensino, que não são adequadas para alunos surdos, bem como a falta de capacitação de muitos profissionais que atuam com este grupo de alunos. Podemos citar, também, como aspecto de entrave na aprendizagem dos alunos surdos, a questão relacionada a exclusão, vivenciadas não só por eles, mas por todas as pessoas com necessidades especiais na sociedade, de forma em geral.

Procurando dar um novo contexto a educação de pessoas com necessidades especiais, surge a perspectiva educacional inclusiva, a qual, baseando-se no princípio da Educação Para Todos, propõe a articulação entre a Educação Especial e o sistema regular de ensino, adotando uma postura de respeito e valorização à diversidade. Em tese a proposta inclusiva visa desenvolver valores e práticas que eliminem, ou ao menos minimizem barreiras físicas, peda- gógicas e de comunicação, possibilitando a igualdade de oportunidades durante o processo educativo e garantindo, assim, uma educação de qualidade a todos os alunos, inclusive àqueles que apresentam necessidades educativas especiais.

Estudos realizados na última década do século XX e início do século XXI por diversos autores, dentre eles Poker (2001), oferecem contribuição à educação de alunos surdos na escola comum. Os referidos estudos ressaltam a importância da valorização das diferenças no convívio social e o reconhecimento do potencial de cada ser humano. O autor afirma:

(...) Deficiências das trocas simbólicas, ou seja, o meio escolar não expõe esses alunos a solicitações capazes de exigir deles coordenações mentais cada vez mais elaboradas que favorecerão o mecanismo da abstração reflexionante e consequentemente os avanços cognitivos. (POKER, 2001, p. 300)

Nesse sentido a Geografia escolar deverá auxiliar, de forma significativa, para a formação de sujeitos críticos e autônomos, possibilitando que estes se tornem capazes de compreender a produção e organização espaciais. Dessa forma, sobretudo considerando a proposta de estudo da Paisagem de forma inclusiva, faz-se necessário pensar em metodologias que efetivem o processo de ensino-aprendizagem, para que os alunos surdos possam compreender $\mathrm{e}$ construir uma melhor relação entre eles e o meio ambiente. Sobre o assunto Cavalcanti (2012), afirma que:

O ensino é um processo dinâmico que envolve três elementos fundamentais: o aluno, o professor e a matéria. Os três elementos são interligados, são ativos e participativos, sendo que a ação de um deles influencia a ação dos outros. $\mathrm{O}$ aluno é sujeito ativo que entra no processo de ensino aprendizagem com sua bagagem intelectual, afetiva e social [...]. (CAVALCANTI, 2012, p.48)

Partindo dessa perspectiva, o ensino de geografia para alunos surdos, deve valorizar a construção do conhecimento a partir de interações entre professor - conteúdo - aluno, valorizando o conhecimento prévio que o aluno trás consigo, sobretudo aquele relacionado a seu espaço de vivência, capacitando-o para ir além do senso comum, promovendo efetivamente a construção e aquisição do conhecimento. Assim, não há como continuar com práticas que privilegiam somente a memorização e as repetições, sendo que o foco, como destacado por Callai (2012, p.74) é "[...] analisar a sociedade e o mundo a partir da espacialidade dos fenômenos [...]" e "[...] trabalhar essa realidade de modo que aluno se entenda como sujeito que está dentro dessa realidade $[. .]$.$" .$ 
Outro aspecto importante a ser levado em conta, para um melhor aprendizado do aluno surdo, diz respeito a forma como este conteúdo será trabalhado. Deve-se considerar a língua utilizada por este grupo, no caso a Libras sua língua natural, e os aspectos ligados a questão visual, sendo estes fatores determinantes, para que ocorra uma educação inclusiva e mais significativa para o aluno surdo.

Desta forma alguns questionamentos se fazem necessários: como trabalhar os aspectos relacionados as transformações da Paisagem de forma clara e objetiva para pessoas surdas? Como tornar as aulas sobre a categoria Paisagem interessante e atraente para este grupo de aluno?

As respostas a estas perguntas estão diretamente relacionadas a metodologia utilizada pelo profissional da Geografia, que deve despertar no aluno surdo à visão de mundo necessária para que ele compreenda a relação do homem com a natureza, e as transformações provocadas por essa relação tanto na esfera local como mundial. Cabe, assim, ao professor de Geografia dar suporte ao aluno surdo, utilizando-se de materiais visuais e concretos que facilite o aprendizado e uma melhor relação entre o aluno e o meio ambiente.

Partindo desse pressuposto sentimos a necessidade de estarmos tratando a educação com um enfoque pedagógico diferente, no qual as pessoas que apresentam essa especificidade possam ser agentes da construção do conhecimento, ou seja, possam compreender melhor o mundo que os cercam, de maneira mais consciente e crítica. Cavalcanti, (1991) faz a seguinte observação:

\begin{abstract}
(...) Os alunos não conseguem formar um raciocínio geográfico necessário à sua participação ativa na sociedade; não conseguem assimilar de modo autônomo e criativo as bases da ciência geográfica que propiciem a formação de convicções e atitudes a respeito da espacialidade da prática social. Também não conseguem formar relações entre os conteúdos que são transmitidos nas aulas de geografia e as determinações espaciais que permeiam, direta ou indiretamente, sua prática social diária. Por não entenderem a importância dos conteúdos de Geografia para suas vidas, os alunos se comportam na sala de aula "formalmente", ou seja, cumprem deveres de alunos para que possam conseguir aprovação da escola, sem se envolverem com os conteúdos estudados. (CAVALCANTI, 1991, p.278).
\end{abstract}

Nesse sentido cabe ao professor de Geografia despertar o interesse do aluno sobre o tema estudado, não apenas levando-o a compreender os conceitos fundamentais da Geografia, mas também orientar esses alunos à aplicar esses conceitos de forma prática em suas vidas. Se para a maioria dos alunos tais correlações podem parecer difíceis de acontecer, o que dizer dos alunos surdos, que apresentam características e singularidades específicas, as quais muitas vezes os docentes não conseguem perceber. E se percebem, na maioria das vezes, não estão preparados para atender essa realidade.

Sendo assim propõe-se um ensino sobre Paisagem com características específicas para alunos surdos, um ensino que leve os mesmos a compreender melhor a dinâmica e os processos que envolvem o homem e a natureza.

\section{DISCUSSÃO TEÓRICO-METODOLÓGICA DA PAISAGEM}

Paisagem é considerada uma possibilidade para os estudos geográficos, mas recebe bastante crítica pela sua subjetividade. Sua clássica definição, encontrada na maioria dos dicionários, a considera como uma porção do território avistada por um observador a partir de um determinado ponto, que privilegia essencialmente os aspectos visíveis. Trata de uma definição que abarca desde o senso popular até a definição por parte dos estudiosos. Yves Lacoste (1977) traz alguns termos para apreender a noção de paisagem, dizendo que "paisagem é uma porção do espaço terrestre que se pode ver num certo ponto de observação".

Segundo Sauer (apud CORRÊA, 1998, p. 9): “A paisagem cultural é modelada a partir de uma paisagem natural por um grupo cultural”. A geografia cultural representa, consequentemente, uma materialização de pensamentos e ações humanas, mas nunca sai do seu caráter físico-material. A Paisagem possui um caráter integrador e relacional, estando associada ao tempo e ao espaço. Sugere uma separação entre a Paisagem natural e cultural. Atribui ao homem à responsabilidade de transformar a Paisagem.

O francês Jean Tricart propôs uma metodologia de delimitação e análise de unidades territoriais, baseada na intensidade, frequência e interação dos processos evolutivos do ambiente, a qual denominou ecodinâmica. A abordagem baseia-se na análise sistêmica e enfoca as relações recíprocas entre os diversos componentes da dinâmica ambiental, com destaque para os fluxos de energia e materiais no ambiente. As unidades ecodinâmicas são classificadas em termos de degradação ou conservação segundo três estágios: "meios estáveis", "meios intergrades" e "meios fortemente instáveis" (TRICART, 1977). 
Nos meios estáveis, a pedogênese é o processo predominante, os meios intergrades se caracterizam pela passagem de um contexto de estabilidade para um contexto de instabilidade, e por último, os meios fortemente instáveis, onde a morfogênese é o elemento predominante na dinâmica natural e fator determinante do sistema natural, ao quais os outros elementos estão subordinados.

Bertrand e Dollfus, no ano de 1973, distinguiram entre as discussões paisagísticas, formas variadas de abordar a paisagem como categoria de análise espacial, duas principais correntes cujos métodos e, sobretudo, as finalidades são diferentes: uma define paisagem como um espaço subjetivo, sentido e vivido e outra que considera a paisagem em si e por si própria, numa perspectiva essencialmente ecológica, tendo como bases situadas na confluência da Geografia com a Ecologia e combinando o global e o setorial, o qualitativo e o quantitativo integrando diferentes escalas de análise. Bertrand, (1972), designou a paisagem como uma ciência diagonal, capaz de abarcar e trabalhar uma visão que nem Ecologia e nem Geografia poderia fazer separadamente.

Bertrand dá uma roupagem bastante completa $\mathrm{e}$ complexa à paisagem. A dimensão assumida pelo termo paisagem para incluir todos os elementos que compõe determinada porção do espaço e, indo, portanto, além dos elementos visíveis, incluindo-se, os elementos invisíveis, os quais regem a evolução de paisagem, sejam eles naturais ou comandados pela ação antrópica. Para o autor, a paisagem não deve ser vista como uma entidade estática, mas sim, composta de movimentos. Esses movimentos são a própria força evolutiva que transforma a paisagem permanentemente.

Para Sotchava (1977), o paradigma sistêmico ou o estudo de geossistemas, aparece como uma nova alternativa para a orientação de pesquisas científicas na moderna Geografia Física e capaz de resolver o grave problema das subdivisões, especializações desta ciência, que acabaram por levar a um distanciamento do seu principal objetivo: a conexão da natureza e da sociedade. A concepção de geossistema para Solchava (1977) vem conferir "precisão aos limites entre a Geografia Física e as outras disciplinas geográficas, definindo ao mesmo tempo, a essência do seu campo de investigações e o seu lugar no conjunto da Geografia". B e rtrand, importa o geossistema, primeiramente concebendo-o como categoria taxonômica e, posteriormente, reconhecendo ser ele apenas um modelo teórico da apreensão da paisagem, definindo como categoria espacial caracterizada por uma relativa homogeneidade dos seus componentes, cuja estrutura e dinâmica resulta interação entre o "potencial ecológico", a "exploração biológica" e a "ação antrópica" e que se identifica por um mesmo tipo de evolução. Para ele o geossistema é um fenômeno natural que inclui todos os elementos da paisagem como um modelo global, territorial e dinâmico, aplicável a qualquer paisagem concreta.

O conceito de geossistema inclui, necessariamente, o conceito de paisagem e ambos se identificam. Nesse caso, o geossistema como modelo teórico e a paisagem, como categoria de análise espacial. Os conceitos associam uma forma comum de análise sistêmica muito vigorosa para Ciência Geográfica, mas há que se reconhecer o seu caráter demasiado naturalista.

\section{O SISTEMA TAXONÔMICO DE BERTRAND}

Bertrand (1971) apresenta seu sistema de classificação taxocorológico das paisagens, comportando seis níveis tempero-espaciais: a zona, o domínio e a região natural (níveis superiores) e geossistema, as geofácies e o geótopo (unidades inferiores). Entretanto, suas pesquisas centraram-se nas unidades inferiores, onde ele destaca o geossistema como escala mais apropriada para os estudos dos fenômenos antrópicos, por ser uma unidade dimensional compreendida entre alguns quilômetros quadrados. Dentro do geossistema, temos as geofácies, unidade fisionomicamente homogênea, caracterizada por "uma mesma fase de evolução geral". Sua dimensão compreende algumas centenas de metros quadrados, em média. O geótopo corresponde à "menor unidade homogênea diretamente discernível no terreno", que compreende dimensões entre o metro quadrado ou mesmo o decímetro quadrado.

Depois da proposta de Bertrand (1971), a relação entre os elementos passa a ser mais importante do que os elementos em si, quando tratados isoladamente, isto é, as conexões instauradas entre cada um dos elementos (da paisagem), tornam-se determinantes na compreensão da dinâmica geral da paisagem. Entendemos isto, quando se destaca que 'por essa dinâmica interna, o geossistema não apresenta necessariamente uma grande homogeneidade fisionômica. $\mathrm{Na}$ maior parte do tempo, ele é formado de paisagens diferentes que representam os diversos estágios da evolução do geossistema' e a homogeneidade do geossistema se dá mais ao nível 
das relações e dos processos do que da própria expressão fisionômica.

Outro ponto importante na proposta de Bertrand (1971) é quando ressalta a necessidade de uma reflexão interdisciplinar, no afã de explorar técnicas específicas de outras disciplinas, como a climatologia, geomorfologia, fitossociologia entre outras, numa contribuição para a compreensão da paisagem e resolução dos problemas que, segundo ele "não pode ser realizado senão no quadro de uma geografia física global".

O sistema taxonômico apresentado por Bertrand (1971) reflete sua preocupação quanto às escalas de pesquisa e a delimitação e cartografação das paisagens, dentro de uma concepção dinâmica, onde destaca três diretrizes principais que devem ser trilhadas para a delimitação das unidades de paisagem. Primeiro, destaca a priorização na busca das "descontinuidades objetivas da paisagem", ao invés de impor categorias pré-estabelecidas. Segundo, a paisagem deve ser definida tal como ela se apresenta, não tentando estabelecer uma síntese "média", pela superposição de unidades elementares, quer pela técnica cartográfica ou pela técnica matemática, o que exclui a possibilidade de uma relação dialética entre os seus elementos. Neste caso, destaca o autor, "a delimitação será mais grosseira, mas as combinações e as relações entre os elementos, assim como os fenômenos de convergência aparecerão mais claramente". Por último, ressalta a necessidade de uma referência escalar, ou seja, situar as paisagens na dupla perspectiva do tempo e do espaço.

\section{O ESTUDO DA PAISAGEM NA PERSPECTI- VA DO ALUNO SURDO A PARTIR DE UMA VI- SÃO FREIREANA}

Apresento a seguir, os principais aspectos que fundamentam a teoria de Paulo Freire, procurando fazer uma correlação entre o estudo da Paisagem e alunos surdos.

A dinâmica dos conceitos elaborados por Paulo Freire, se fundamentam nos seguintes princípios: amorosidade; dialogicidade; investigação temática; codificação-descodificação e problematização.

A amorosidade pode ser entendida como um ato de compromisso com a transformação da sociedade, em favor dos oprimidos. Freire (2005) nos afirma que o amor é um ato de coragem, porque representa o comprometer-se com os oprimidos e sua causa.

A dialogicidade inicia-se com a reflexão sobre o ato de educar, se operacionaliza na investigação do tema e na pesquisa da realidade envolvida, que passam a ser compreendidas como temas geradores e problematizados para trans- formação da situações.

O processo de investigação temática é um ato pedagógico que demanda pesquisa e tomada de decisão. A investigação nos moldes freireanos reafirma a dialogicidade entre professores e alunos, para o desenvolvimento de temas geradores.

O processo de codificação-descodificação, pode ser entendido como um processo dialógico-problematizador, que corresponde a um "esforço de propor aos indivíduos dimensões significativas de sua realidade, cuja análise crítica lhes possibilite reconhecer a interação de suas partes" (Freire. 2005, p.111).

O processo de problematização não se limita apenas em conhecer a realidade proposta, baseia-se na busca da transformação dessa realidade. Não se problematiza a realidade apenas para conhecê-la, problematiza-se para modificá-la.

O desenvolvimento de recursos e métodos para o processo de ensino-aprendizagem tem sido mediado pelo uso de vários fatores que contribuem para o processo de construção do conhecimento, tanto em sala de aula como fora dela. No caso dos surdos, as ferramentas mais utilizadas para a construção do conhecimento, são aquelas ligadas a observação e a comunicação em Libras. Atreladas a Libras e a observação, a Teoria proposta por Paulo Freire, contribui enormemente para o desenvolvimento de um proposta de ensino que contemple a educação de surdos, sobretudo vinculada ao estudo da Paisagem.

A partir dos conceitos propostos por Paulo Freire, dentro da chamada Pedagogia Dialógica-problematizadora, a aprendizagem dos alunos surdos pode ser compreendida em sua dimensão transformadora e emancipatória, cujo objetivo é construir coletivamente novas relações com o ambiente, e com a Paisagem que os cercam.

Para a execução dessa pesquisa, foi utilizada como instrumento metodológico a pesquisa-ação. Thiollent (2000) considera que o eixo metodológico da pesquisa-ação é a articulação entre a produção do conhecimento para a conscientização e solução dos problemas socialmente relevantes, tendo como proposito construir de forma coletiva e participativa, novas relações dos alunos surdos, com o ambiente e com a Paisagem na qual estão inseridos.

Dentro dessa proposta Freireana, unida a pesquisa-ação, foi trabalhado com alunos surdos do $6^{\circ}$ ao $9^{\circ}$ ano do ensino fundamental, de uma escola pública de Brasilia, as principais características da Paisagem e suas transformações. A pesquisa foi realizada com um grupo de dezoito alunos 
surdos, estudantes da sala de recursos com orientação do professor de Geografia. Os alunos ouvintes não participaram da pesquisa em função da especificidade da sala de recursos atender apenas alunos surdos.

Inicialmente ocorreu uma conversa com alunos sobre as questões ambientais, voltadas para os aspectos relacionados a Paisagem. Foi discutido com os alunos surdos o conceito de Paisagem, para que fosse realizado o processo de codificação-descodificação, e as possíveis convergências e divergências sobre $\mathrm{o}$ assunto.

Após o debate com os alunos, no qual contamos com a participação de um intérprete de Libras, que realizou a interpretação para a língua natural dos surdos, Libras, foi definido o tema gerador para a pesquisa. $\mathrm{O}$ tema definido pelos alunos está relacionado a Paisagem e as transformações provocadas pelo homem.

Em seguida foi apresentado aos alunos um vídeo sobre o tema escolhido. O vídeo apresentado aos alunos, demonstrou as transformações provocadas na Paisagem em função da proximidade com um lixão, no qual perceberam que o elemento humano é determinante para as modificações ocorridas na Paisagem, sobretudo em relação ao lixo produzido e descartado pelo homem na natureza.

Após assistirem o vídeo e os comentários feitos pelo professor com a participação de um intérprete de Libras, os alunos dirigiram-se ao lixão da cidade, local em que observaram todas as transformações provocadas na Paisagem, pelo acumulo do lixo gerado pelo homem. Nessa visita os alunos compreenderam melhor as principais transformações ocorridas na Paisagem, através de elementos que exemplificam as principais questões apresentadas no vídeo.

Para os alunos surdos, a aprendizagem de temas relacionados a Paisagem, com a utilização dos pressupostos metodológicos de Paulo Freire, associados a pesquisa-açao, tornaram a aprendizagem mais significativa, tendo em vista que os alunos criaram seu próprio conceito de Paisagem a partir das experiências vivenciadas, compreendendo assim as transformações ocorridas e provocadas pelo homem sobre a Paisagem.

Esses elementos forneceram os requisitos necessários para que fossem elaborados soluções para possíveis tema geradores da aprendizagem, passando pelo diálogo sobre o tema, procurando redesenhar, reinterpretar e transformar a aprendizagem dos alunos surdos. Tendo em vista, que ao não se utilizar uma metodologia adequada, e composta de elementos significativos para os alunos surdos, eles muitas vezes não farão as articulações necessárias para que ocorra uma aprendizagem significativa e transformadora.
A partir da utilização de elementos relacionados a observação, comunicação em Libras, vídeo sobre o tema escolhido e visita ao lixão da cidade, a aprendizagem dos alunos surdos, passa por uma etapa de reconhecimento do outro, no processo de construção do saber. Neste sentido, Barbato comenta:

o que é dito em sala, é instituído em contexto específico, que direciona a atuação do professor na construção de significados e nas interlocuções que se seguem, é um processo de negociação em que as palavras "sinais" sofrem deslocamento a fim de serem apreciadas e interpretadas pelos interlocutores. Esse direcionamento é ideológico e emocional, ou seja, adquire sentidos vivenciais que despertam e motivam a pluralidade discursiva, o contraditório e a negociação em busca de denominadores comuns. (BARBATO, 2013, P16).

Ao trabalhar temas relacionados a geografia com alunos surdos, o professor deve atuar como um mediador, construindo o conhecimento de forma conjunta, utilizando as ferramentas que darão significado a aprendizagem dos alunos. Neste caso propõe-se o uso da metodologia Freireana, da Libras e da pesquisa-ação, no processo de observação da Paisagem, seja ela in loco ou através de imagens.

O processo de mediação está diretamente relacionado ao grupo de pessoas envolvidas em um mesmo contexto de aprendizagem. Em se tratando de pessoas surdas, essas considerações devem partir do vivenciado, do conhecido, do visto, do lido, ou seja, serão considerações que construirão as bases da aprendizagem, visando teorizar e aprofundar o estudo da Paisagem.

Dessa forma, a representação estabelecida pela Paisagem no estudo da geografia, fornece elementos significativos e concretos para os alunos surdos, pois desenvolve o raciocínio, através de relações vividas, imaginadas e até mesmo desconhecidas, possibilitando a construção coletiva do conhecimento, permitindo estabelecer um marco no tempo e no espaço, relacionada a determinada Paisagem, no antes e depois de sua visualização.

Santos (1978, p. 67) reforça o caráter dinâmico da Paisagem ao afirmar que:

A paisagem é um conjunto de forma que, num dado momento, exprimem heranças que representam as sucessivas relações localizadas entre o homem e a natureza. A paisagem se da como um conjunto de objetos reais - concretos. Neste sentido a paisagem é transtemporal, juntando objetos passados e presentes, uma construção transversal. A paisagem existe, através de suas formas, criadas em momentos históricos diferentes, porém coexistindo no momento atual. (SANTOS, 1996, p. 83-84).

Baseando-se nos comentários e observações citados anteriormente, percebemos que o estudo da Paisagem através da geografia dentro de uma visão Freireana, embasados 
pela pesquisa-ação, pode oferecer uma compreensão real de conceitos considerados abstratos para os alunos surdos, dentre eles: o conceito de espaço geográfico, de Paisagens preservadas e transformadas, desenvolvimento sustentável, produção, consumo e degradação ambiental entre outros. Facilita-se, assim, o processo de apropriação e elaboração conceitual de temáticas relacionadas a Paisagem, que muitas vezes parecem não ser compreendidas com clareza pelos alunos surdos.

\section{CONSIDERAÇÕES FINAIS}

As considerações aqui apresentadas, partiram das observações e dificuldades presenciadas, em sala de aula, ao trabalhar com alunos surdos. Os profissionais das escolas regulares em geral, que trabalham com alunos que apresentam algum tipo de diferença, não dispõem de mecanismos de ensino-aprendizagem que facilitem as trocas simbólicas, que os levarão a abstração e a avanços cognitivos significantes.

Partindo desse pressuposto, refletimos sobre o estudo da Paisagem em geografia, para alunos surdos, procurando caracterizar o ensino-aprendizagem deste grupo, em relação aos temas ambientais a partir do pensamento de Paulo Freire, com utilização da pesquisa-ação como metodológico. Nessa perspectiva, o processo de aprendizagem é resultado da interação e da mediação que ocorre entre professor e aluno, devendo-se considerar as experiências e os conceitos que os alunos trazem consigo, e que possam resultar em novas reflexões e novas atitudes dos alunos surdos em relação a Paisagem.

Os conceitos utilizados para o desenvolvimento da pesquisa foram os de amorosidade, dialogicidade, investigação temática, codificação-descodificação e problematização, que tem por objetivo levar a um maior empoderamento individual e coletivo dos alunos surdos, constituindo assim um processo emancipatório e libertador.

Através da utilização da pesquisa-ação como metodologia, pode-se criar novas relações dos alunos surdos com a Paisagem, dentro de uma visão participativa, emancipatória e socialmente justa.

Outro aspecto imprescindível na aprendizagem dos alunos surdos, e a utilização da língua brasileira de sinais "Libras", situação em que os alunos demonstram sua capacidade de comunicação e de expressão do conhecimento sobre determinado tema. Ao fazermos esta abordagem, a aprendizagem passa a ter um valor significativo e individualizado para o aluno, fazendo com que ele compreenda melhor o mundo em sua volta e suas transformações.

O estudo da geografia para alunos surdos, com a utilização de recursos pautados na observação, dentro de temas relativos a Paisagem, constituirão ferramentas fundamentais de integração entre aluno e sociedade, levando-os a criarem seus próprios conceitos, e sobretudo capacitando-os no sentido de interligar os pontos de complexidade que lhes são apresentados.

Assim sendo, Infere-se que o professor de Geografia deva trabalhar com esses alunos questões da comunidade em que vivem, discutindo, com eles, os problemas e estimulando-os a pensar em possíveis soluções. $\mathrm{O}$ objetivo é tornar compreensíveis de fato algumas ideias que se apresentam de forma abstrata para os alunos, optando por políticas de investigação que facilitem a aprendizagem a todos, estimulando assim, a elaboração, dos conceitos relativos a Paisagem, bem como a percepção de suas transformações.

A oportunidade de apresentar outros olhares sobre a Paisagem, fará com que os alunos interajam e se sintam membros importantes do lugar onde vivem, fortalecendo, assim, seu sentimento de pertencimento. Tal postura poderá constituir-se em um elemento atrativo e motivador no desenvolvimento das relações de ensino-aprendizagem, entre professor, aluno e comunidade.

\section{REFERÊNCIAS BIBLIOGRÁFICAS}

BERALDO, R; BARBATO, S. Instrumentos Pedagógicos para Preparação e Dinamização de Aulas com o uso das TIC e da Internet. Curso de Atualização em Práticas Pedagógicas. Brasilia: Cead / UNB, 2013.

BERTRAND, G. Paisagem e geografia física global: esboço metodológico. Cadernos de Ciências da Terra, n. 13, Instituto de Geografia da USP, 1971, 27p.

CALLAI, H. C. Educação Geográfica: ensinar e aprender geografia. In: CASTELLAR, S. M. V \& MUNHOZ, G. (ORGs). Conhecimentos escolares e caminhos metodológicos. São Paulo: XAMÃ, 2012.

CAVALCANTI, L. S. O ensino crítico de geografia em escolas públicas do ensino fundamental. Dissertação de mestrado. Goiânia: Faculdade de Educação/UFG 1991.

COSTA, J. Pistas sinestésicas: uma estratégia facilitadora para a alfabetização de pessoas surdas. Revista Espaço. Rio de Janeiro: INES. $N^{\circ}$ 18/19, pp.106-111, DEZEMBRO/2002-JULHO/2003.

FREIRE, P. Pedagogia do oprimido. 42. ed. Rio de Janeiro: Paz e Terra, 2005. 
.Criando métodos de pesquisa alternativa: aprendendo a fazer melhor através da ação. In: BRANDÃO,C.R. (org.). Pesquisa participante.3. ed. São Paulo: Brasiliense, 1981, p. 34-41.

LACOSTE, YVES. A Geografia serve antes de mais nada para fazer a guerra. Lisboa: Iniciativas Editoriais, 1977.

POKER, R. B. Troca simbólica e desenvolvimento cognitivo em crianças surdas: uma proposta de intervenção educacional. UNESP, 2001. 263p. Tese de Doutorado.

SANTOS, M. A natureza do espaço-técnica e tempo, razão e emoção. São Paulo: HUCITEC, 1996.

SAUER, C.O. A Morfologia da Paisagem. 1925. In. ROSENDAHL, Z; CORRÊA, R.L. Paisagem, Tempo e Cultura. Ed. UERJ. Rio de Janeiro1988. p. 12-74.

SOTCHAVA, V.B. O Estudo de Geossistema. In: Métodos em Questão, n.16. São Paulo: USP, 1977.

THIOLLENT, M. Metodologia da pesquisa-ação. São Paulo: Cortez. 2000.

TRICART, J. Ecodinâmica. Rio de Janeiro: IBGE, 1977. 91p.

VESENTINI, J. W. O método e a Práxis: Notas polêmicas sobre a Geografia tradicional e geografia crítica. Terra Livre. São Paulo: AGB, no 2, jul.1997.

\section{Correspondência do autor:}

Jean Volnei Fernandes

e-mail: j.volnei@uol.com.br

Artigo recebido em: 27/01/2016

Revisado pelos autores em: 08/05/2016

Aceito para publicação em: 18/06/2016 